\title{
Solvent-Controlled Chemoselectivity in the Photolytic Release of Hydroxamic Acids and Carboxamides from Solid Support
}

Qvortrup, Katrine; Petersen, Rico G; Dohn, Asmus Ougaard; Møller, Klaus Braagaard; Nielsen, Thomas E

Published in:

Organic Letters

Link to article, DOI:

10.1021/acs.orglett.7b01386

Publication date:

2017

Document Version

Peer reviewed version

Link back to DTU Orbit

Citation (APA):

Qvortrup, K., Petersen, R. G., Dohn, A. O., Møller, K. B., \& Nielsen, T. E. (2017). Solvent-Controlled Chemoselectivity in the Photolytic Release of Hydroxamic Acids and Carboxamides from Solid Support. Organic Letters, 19(12), 3263-3266. https://doi.org/10.1021/acs.orglett.7b01386

\section{General rights}

Copyright and moral rights for the publications made accessible in the public portal are retained by the authors and/or other copyright owners and it is a condition of accessing publications that users recognise and abide by the legal requirements associated with these rights.

- Users may download and print one copy of any publication from the public portal for the purpose of private study or research.

- You may not further distribute the material or use it for any profit-making activity or commercial gain

- You may freely distribute the URL identifying the publication in the public portal 


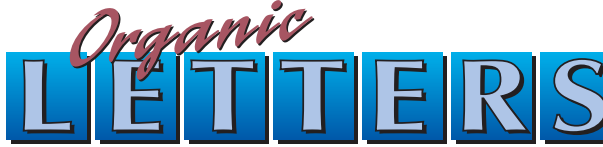 \\ Solvent-Controlled Chemoselectivity in the Photolytic Release of ${ }_{2}$ Hydroxamic Acids and Carboxamides from Solid Support
}

\author{
${ }_{3}$ K. Qvortrup, ${ }^{*} \dagger \oplus$ Rico G. Petersen, ${ }^{\dagger}$ Asmus O. Dohn, ${ }^{\dagger}$ Klaus B. Møller, ${ }^{\dagger}$ and T. E. Nielsen ${ }^{\dagger,+(0)}$ \\ $4{ }^{\dagger}$ Department of Chemistry, Technical University of Chemistry, DK-2800 Kgs. Lyngby, Denmark \\ $5{ }^{\ddagger}$ Singapore Centre for Environmental Life Sciences Engineering, Nanyang Technological University, Singapore 637551, Singapore \\ 6 S Supporting Information
}

7 ABSTRACT: The synthetic utility and theoretical basis of a 8 photolabile hydroxylamine-linker are presented. The devel9 oped protocols enable the efficient synthesis and chemo10 selective photolytic release of either hydroxamates or 11 carboxamides from solid support. The bidetachable mode of 12 the linker unit is uniquely dependent on the solvent.

13 Hydroxamic acids are obtained by performing photolysis in protic solvents, whereas photolysis in aprotic solvents enables the 14 selective release of carboxamides.
15 Tydroxamic acids have been the source of much $16-$ biochemical interest in recent years. ${ }^{1}$ Therefore, the use 17 of solid-phase ${ }^{2}$ combinatorial chemistry ${ }^{3}$ for high-throughput 18 generation of structurally diverse hydroxamic acids is highly 19 relevant. Although hydroxamic acids may be obtained by direct 20 cleavage of resin-bound esters with hydroxylamine derivatives, ${ }^{4}$ 21 this strategy requires an excess of hydroxylamine and/or 22 addition of base which complicates postcleavage workup. 23 Several approaches involving resin-bound hydroxylamine link24 ers have been reported. ${ }^{5}$ However, these hydroxamate linkages 25 suffer from only being cleavable under acidic conditions, which 26 limits the range of chemical transformations applicable to the 27 solid-phase synthesis of structurally diverse hydroxamic acids. 28 Therefore, other cleavage principles are necessary in order to 29 provide complex molecules assembled through a diverse range 30 of chemical reactivity. A linker system that can be cleaved under 31 photolytic conditions may be considered truly orthogonal in 32 this context. ${ }^{6}$ Futhermore, photolytic cleavage offers a mild 33 method of cleavage which is particularly attractive for the direct 34 release of screening compounds into biological screens without 35 contamination by cleavage reagents.

36 We now wish to report a complete study on a photolabile 37 linker based on the $o$-nitroveratryl group ${ }^{7}$ capable of releasing 38 hydroxamates upon UV irradiation. Uniquely, this linker unit 39 may function as a "bidetachable" system. By simply varying the 40 reaction solvent, the photolysis can be controlled to provide 41 either $\mathrm{C}-\mathrm{O}$ or $\mathrm{C}-\mathrm{N}$ bond cleavage, which allows for controlled 42 release of the hydroxamate or carboxamide, respectively (Figure 43 1). This strategy may introduce further diversity into target 44 molecules and compound libraries. Linker 4 was readily 45 prepared in a few high-yielding steps (Scheme 1$)^{8}$ before 46 being explored as a hydroxamate-releasing linker. A $N$ - $[(1 H-$ 47 benzotriazol-1-yl)(dimethylamino)-methylene]-N-methyl48 methanaminium tetrafluoroborate $N$-oxide (TBTU)-mediated 49 coupling of 4 to a Rink linker attached to the commercially 50 available amino-functionalized support $\left(\right.$ PEGA $\left._{800}\right)$ afforded the
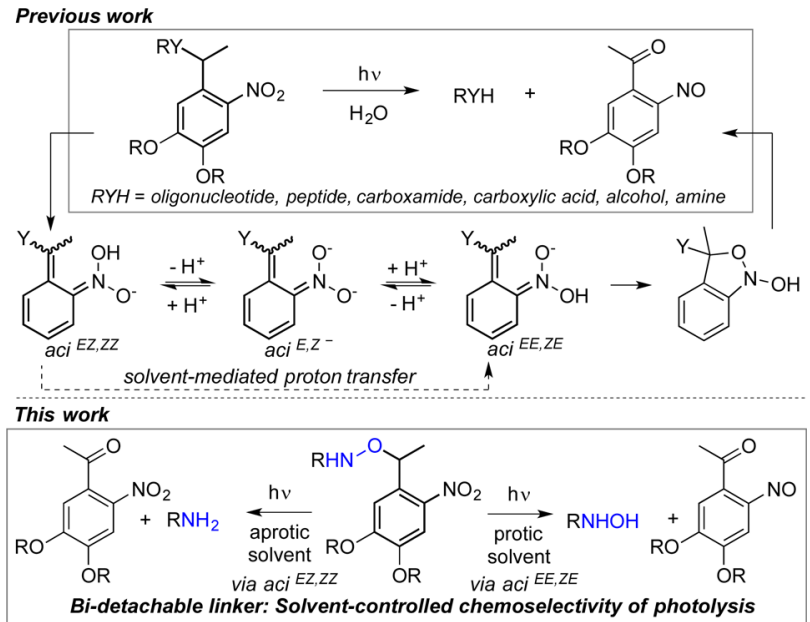

Figure 1. 4,5-Dialkoxy-2-nitrobenzyl moiety in photolabile linkers for solid-phase synthesis.

hydroxylamine-functionalized photolabile support. Using stand- 51 ard TBTU-mediated peptide coupling reactions, derivative $\mathbf{5 a} 52$ was synthesized as a simple and easily monitorable model 53 system. Photolytic cleavage was carried out on resin suspended 54 in $\mathrm{H}_{2} \mathrm{O} / \mathrm{MeOH}(4: 1)$ by irradiating for $30 \mathrm{~min}$ at rt with 36555 $\mathrm{nm}$ light using an LED UV-lamp. Analysis of the released 56 material via RP-UPLC, however, showed release of two 57 products: the hydroxamate $7 \mathbf{a}$ and the carboxamide $8 \mathbf{a}$ resulting 58 from $\mathrm{C}-\mathrm{O}$ and $\mathrm{N}-\mathrm{O}$ cleavage, respectively, in a 3:4 ratio. $\quad 59$

The nature of the solvent ${ }^{9}$ and the acidity of the solution ${ }^{10,11} 60$ have been demonstrated to have pronounced effect on the 61 kinetics and equilibrium position of aci-nitro compounds 62 (Figure 2). We first explored the solvent effects in the $63 \mathrm{f} 2$

Received: May 8, 2017 
Scheme 1. (A) Synthesis of Fmoc-Protected HydroxylamineFunctionalized Carboxylic Acid Linker (4); (B) Application of Linker 4 in Solid-Phase Peptide Synthesis (SPPS) for the Photolytic Release of Peptide Hydroxamic Acids and Carboxamides



64 photolysis of $\mathbf{6 a}$ on the level of final product formation. The 65 photoreaction was studied by photolyzing aliquots of the resin 66 6a in various solvents and determining the product distribution 67 via HPLC analysis. Because the solvent also influences the 68 swelling and solvation properties of the support, the obtained 69 results are merely qualitative. While this technique did not 70 allow us to quantify the amount of products formed, it did 71 provide an expedient method to determine the relative 72 photoproduct formation. Selected product yield profiles are 73 listed in Table 1 (for a comprehensive list consult the 74 Supporting Information (SI)). It is evident that the solvent 75 has a strong influence on the product ratio of the reaction and 76 some general conclusions may be drawn. Polar solvents favor 77 formation of the hydroxamic acid product $7 \mathbf{a}$, while apolar 78 solvents mainly give the carboxamide product $8 \mathbf{a}$. In particular, 79 the polar fluorinated alcohol, hexafluoroisopropanol (HFIP), 80 with a high hydrogen-bond-donating ability led to hydroxamic 81 acid product $7 \mathbf{a}$ with high selectivity. Apolar solvents favor 82 formation of the carboxamide product $8 \mathbf{a}$ over hydroxamate 83 product 7 a. Notably, when using mesitylene, carboxamide 84 product 8a was formed exclusively.
Table 1. Relative Product Yields for Photolysis of 5a at 360 $\mathrm{nm}$ in Various Solvents

\begin{tabular}{|c|c|c|}
\hline entry $^{a}$ & solvent & product $7 \mathbf{a}: 8 \mathbf{a}^{b}$ \\
\hline A & mesitylene & $0: 100$ \\
\hline B & $\mathrm{MeOH} / \mathrm{H}_{2} \mathrm{O}(1: 4)$ & $67: 33$ \\
\hline $\mathrm{C}$ & $\mathrm{H}_{2} \mathrm{O}$ & $60: 40$ \\
\hline $\mathrm{D}$ & HFIP & $98: 2$ \\
\hline $\mathrm{E}$ & mesitylene/HFIP (1:1) & $98: 2$ \\
\hline
\end{tabular}

${ }^{a}$ Photolytic cleavage was carried out for $0.5 \mathrm{~h}$ with an LED UV-lamp $(360 \mathrm{~nm}) .{ }^{b}$ Product distribution was determined by RP-HPLC.

The effect of Lewis acid catalysis on the photoreaction of 5a 85 has also been investigated (SI). The qualitative studies showed 86 that a wide range of Lewis acids favor the formation of the 87 hydroxamate product. The most efficacious Lewis acid was 88 found to be $\mathrm{BF}_{3}$, giving high selectivity toward formation of the 89 hydroxamate product $\mathbf{8 a}$.

\section{0}

It is well-known that $o$-nitroveratryl compounds upon 91 irradiation undergo a Norrish Type II $\beta$-hydrogen abstraction 92 to give the biradical intermediate $11,^{12}$ which after photo- 93 isomerization forms the E,Z-12 and Z,Z-12 isomers (Figure 2). 94 From there it can again undergo isomerization to the E-aci- 95 nitro forms $14^{E E}$ and $14^{Z E}$. Measurements of aci-nitro transients 96 have confirmed the presence of $13^{-}$as an intermediate between 97 12 and $14,{ }^{11}$ and direct isomerization of $\mathbf{1 2}$ to $\mathbf{1 4}$ by rotation 98 about the $\mathrm{C}=\mathrm{N}$ bond has been excluded. ${ }^{13,14}$ Also, the 99 conversion of $\mathbf{1 2}$ to $\mathbf{1 4}$ via direct proton shift between the two 100 oxygen atoms of the aci-nitro group (without participation of a 101 water molecule) seems unlikely. ${ }^{15,11}$ The activation barrier 102 computed by our density functional theory calculations yielded 103 a barrier of $123 \mathrm{~kJ} \mathrm{~mol}^{-1}$ for this direct proton shift in the 104 species 12 derived from 9, where $R^{1}=P h, R^{2}=$ Me. 105 Furthermore, inclusion of a single water molecule to mediate 106 the shift of this proton was computed to lower the activation 107 barrier by at least $81 \mathrm{~kJ} \mathrm{~mol}^{-1}$ (see SI for computational 108 details). The presence of additional water molecules in bulk 109 solution should lower the activation barrier for water-mediated 110 proton exchange even further. ${ }^{15}$ Taking this solvation effect 111 into account, water-mediated proton exchange (or proton 112 transfer mediated by other protic solvents) via the anion $\mathbf{1 3}$ can 113 be assumed to be the most likely path between the nitronic acid 114 isomers 12 and 14, with an activation barrier of only a few kJ 115 $\mathrm{mol}^{-1}$. Based on this discussion, we assume that the equilibrium 116 between the two possible protonation sites on the nitronic acid 117

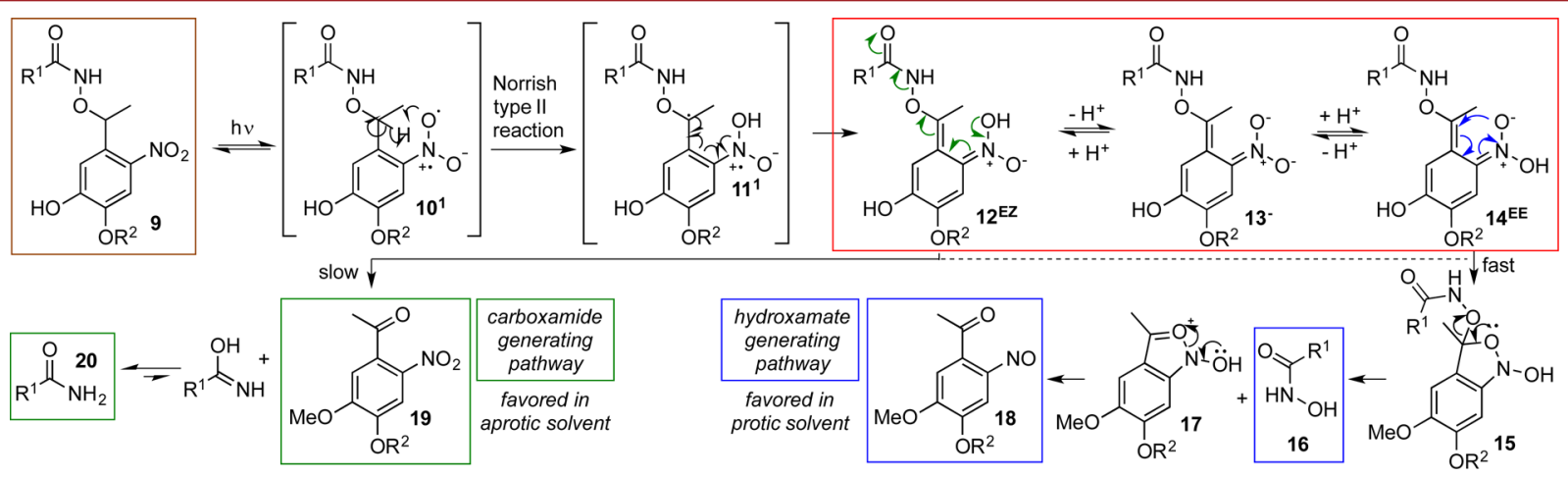

Figure 2. Proposed mechanism for the photolytic degradation of hydroxamate-functionalized $o$-nitroveratryl derivatives. For simplicity, only the $E$ isomers with regard to the $=\mathrm{C}-\mathrm{OR}$ group are shown. 
118 function is established on the ns time scale in polar protic 119 solutions.

120 It is generally assumed that the decay of the aci-nitro forms is 121 the rate-limiting step in the photoisomerization of $o$-nitrobenzyl 122 derivatives and that cyclization to form intermediate $\mathbf{1 5}$ 123 proceeds only from the neutral aci-tautomer $14 .^{11-13}$ Under 124 conditions where interconversion between the two aci-nitro 125 forms is efficient, we expect the "normal" hydroxamic acid 126 product forming pathway $(\mathbf{1 4} \rightarrow \mathbf{1 5} \rightarrow \mathbf{1 6})$ to be fast. 127 However, in aprotic solvent where ionization to $13^{-}$does not 128 occur, the $Z$-aci-nitro species 12 give rise to a $\mathrm{N}-\mathrm{O}$ bond 129 fragmentation pathway, which generates the amide and 130 nitroketone products 19 and 20 . The proposed mechanism is 131 depicted in Figure 2.

132 To further investigate the photolysis of hydroxamate133 functionalized $o$-nitroveratryl compounds, we synthesized 21 134 (SI) as a model compound and studied the photolysis in 135 solution (Figure 3 ). Hereby we were able to identify the nature

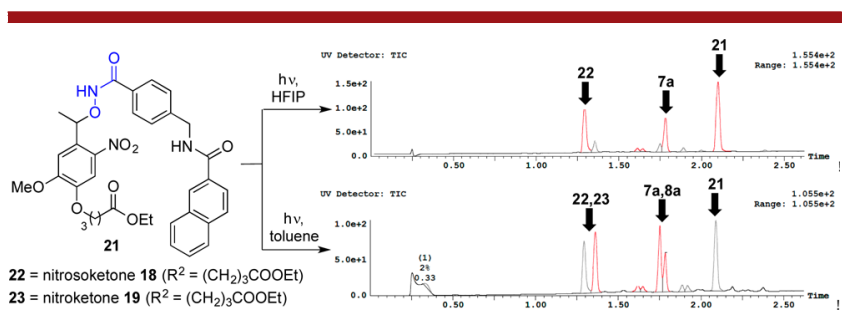

Figure 3. Study of product distribution for the photolytic degradation of 21 in HFIP and toluene, respectively.

136 of byproducts formed in the photolysis of a hydroxamate137 functionalized $o$-nitroveratryl compound. Furthermore, solution 138 phase photolysis experiments provide the opportunity to study 139 the photolysis without influences from swelling and solvation 140 properties of the solid support. Photolysis of 21 was carried out 141 in a broad range of solvents (see SI). The low solubility of 21 142 did not allow an investigation of irradiation experiments in 143 mesitylene and saturated hydrocarbon solvents. In polar 144 solvents and in acidic solutions $\left(\mathrm{CH}_{3} \mathrm{CN}, \mathrm{HFIP}, 1 \%\right.$ TFA in $145 \mathrm{MeOH})$ the hydroxamic acid product formation is the only 146 observed pathway, while the apolar solvent toluene gave a 147 mixture of hydroxamic acid $7 \mathbf{a}$ and carboxamide $\mathbf{8 a}$ in a ratio of 148 1:1. Two examples of our results with 21 are shown in Figure 3. 149 Each peak in the chromatograms is characterized and identified 150 by UPLC-MS. In agreement with our proposed mechanism, we 151 observed from these experiments that the major byproduct 152 formed in polar solvents was 0 -nitrosobenzaldehyde 22, with 153 only minor impurities of 23, while $o$-nitrosobenzaldehyde 22 154 and $o$-nitrobenzaldehyde 23 were formed in a ratio of $\sim 1: 1$ in 155 toluene. The absence of other peaks in the chromatograms 156 indicates that no other side reactions had occurred. Confident 157 with the photolysis strategy, we employed the hydroxylamine 158 linker 4 for the parallel synthesis of a library of putatively 159 HDAC inhibitors ${ }^{16}$ (Table 2 and SI). A Rink linker was 160 positioned between the support and the photolinker unit to 161 optimize and verify attachment chemistry of linker 4 on the 162 solid support. After incubating the supports 5a-e with TFA/ $163 \mathrm{CH}_{2} \mathrm{Cl}_{2}$ (1:1) for $2 \mathrm{~h}$, one major peak corresponding to 164 cleavage of the Rink linker was generally observed $(6 \mathbf{a}-\mathbf{e})$, 165 indicating high efficiency of the attachment chemistry of 4 and 166 high stability of the photolabile unit toward TFA deprotection 167 conditions normally used in standard peptide synthesis 168 procedures. Photolytic cleavage was carried out on 30-100
Table 2. Synthesis and Photolytic Release of Hydroxamates $7 \mathrm{a}-\mathrm{h}$ and Carboxamides $8 \mathrm{a}-\mathrm{h}$

\begin{tabular}{|c|c|c|c|}
\hline \multirow{2}{*}{$\begin{array}{c}\text { entry[a] } \\
\text { A }\end{array}$} & substrate & purity $(\%)^{[b]}$ & yield (\%) \\
\hline & & 6a: 80 & 7a: 59 \\
\hline \multirow{4}{*}{ B } & & $7 \mathbf{a}:>95$ & 8a: 58 \\
\hline & & $\mathbf{8 a}:>95$ & \\
\hline & & 6b: 92 & $7 \mathbf{b}: 61$ \\
\hline & & $7 \mathbf{b}:>95$ & 8b: 53 \\
\hline \multirow{3}{*}{ C } & & $\mathbf{8 b}: 90$ & \\
\hline & & $6 c:>95$ & 7c: 55 \\
\hline & & 7c: $>95$ & 8c: 46 \\
\hline \multirow{3}{*}{ D } & & 8c: $>95$ & \\
\hline & & 6d: 95 & $7 \mathbf{d}: 56$ \\
\hline & & 7d: $>95$ & 8d: 49 \\
\hline \multirow{3}{*}{$\mathrm{E}$} & & $\mathbf{8 d}:>95$ & \\
\hline & & 6e: 94 & 7e: 47 \\
\hline & & 7e: 94 & 8e: 35 \\
\hline & & $\mathbf{8 e}:>95$ & \\
\hline \multirow[t]{2}{*}{$\mathrm{F}$} & & $\mathbf{7 f :}>95$ & 7f: 54 \\
\hline & & 8f: 93 & 8f: 40 \\
\hline \multirow[t]{2}{*}{ G } & & $\mathbf{7 g}:>95$ & $7 g: 48$ \\
\hline & & 8g: 94 & 8g: 46 \\
\hline \multirow[t]{2}{*}{$\mathrm{H}$} & & 7h: 94 & 7h: 63 \\
\hline & & $\mathbf{8 h}:>95$ & 8h: 51 \\
\hline
\end{tabular}

${ }^{a}$ Photolytic cleavage was carried out for $2 \mathrm{~h}$ with an LED UV-lamp $(360 \mathrm{~nm}) .{ }^{b}$ Purity was determined by RP-HPLC.

$\mathrm{mg}$ of resin suspended in appropriate solvent by irradiating for 169 0.5-3 h at rt with $365 \mathrm{~nm}$ light using an LED UV-lamp. We 170 showed the possibility of selectively cleaving these compounds 171 to give the hydroxamate and the carboxamide products, 172 respectively. Selected examples of cleavage of a variety of 173 compounds are presented in Table 2 (for a more elaborate 174 study on cleavage of the full compound library, see SI). From 175 Table 2 it can be concluded that the developed solid-phase 176 methodology is very robust and applicable to a range of both 177 aromatic and aliphatic hydroxamates. The liberated products 178 were recovered in high purity (90-95\%) and satisfactory yields 179 $(35-63 \%)$.

While the linker 4 has been shown to be stable toward both 181 acidic and basic condition, we investigated the utility of the 182 linker for the synthesis of acid- and base-labile substrates. Both 183 hydroxamate functionalized amino acid derivatives containing 184 Boc- $(7 \mathbf{h})$ and Fmoc- $(7 \mathbf{g})$ protected $\alpha$-amino groups, Trt- 185 protected amide (7g), and Pbf-protected guanidinium (7h) side 186 chain groups were successfully released, demonstrating the 187 extraordinary protecting group compatibility of this linker resin. 188

To further demonstrate the synthetic potential of the linker 189 for the generation of more complex structures, we investigated 190 the use of linker 4 for the synthesis of a derivative of a known 191 diketopiperazine (DKP) hydroxamic acid HDAC inhibitor. ${ }^{17}{ }_{192}$

Massive efforts in solid-phase synthesis have strived for the 193 development of synthesis methodology, which systematically 194 generates natural product-like compounds of high spatial 195 complexity. In this context a current limitation is the difficulties 196 faced in the synthesis of acid and base sensitive scaffolds, 197 including racemization-prone structures. To demonstrate the 198 use of linker 4 for the generation of the hydroxamate- 199 functionalized DKP derivative 25, a serine-terminated oligo- 200 meric peptide sequence $\mathbf{2 4}$ was assembled on a hydroxylamine- 201 functionalized photolabile support by standard SPPS protocols. 202 Exposing the resin $\mathbf{2 4}$ to classical periodate oxidation 203 
204 conditions generated the corresponding aldehyde, and 205 subsequent TFA treatment mediated the $\mathrm{N}$-acyliminium 206 cyclization. Rewardingly, photolytic release gave the hydrox207 amate-functionalized DKP-derivative $\mathbf{2 5}$ in high purity (Scheme 208 2).

Scheme 2. Synthesis of a Hydroxamate-Functionalized Fused Natural Product-like DKP Derivative (25)

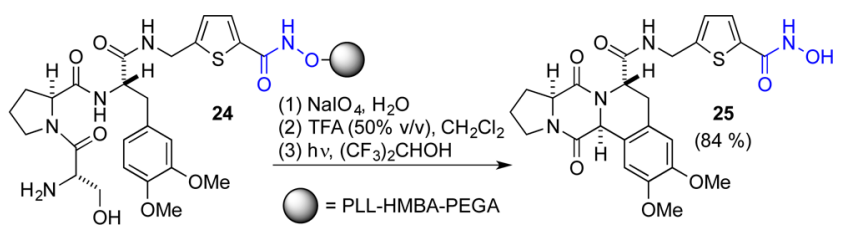

209 In summary, we have developed a photolabile hydroxylamine 210 linker for the synthesis of hydroxamic acids on solid support. 211 The synthesis strategy shows excellent compatibility with a 212 range of structurally diverse compounds. The linker is 213 compatible with most commonly used protecting groups for 214 SPPS and remains intact throughout the multistep synthesis. 215 Products are ultimately released from the solid support in high 216 purity using light. In addition, this linker unit may also function 217 in a bidetachable mode, enabling the release of the 218 corresponding carboxamides when photolysis is performed in 219 an aprotic solvent. Based on results from density functional 220 theory calculations, the present paper provides evidence of the 221 mechanism allowing for the control and selection between 222 these two competing reaction pathways. Finally, we have 223 demonstrated the use of the linker for the generation of a 224 pharmacologically relevant hydroxamate-functionalized natural 225 product-like DKP derivative in high purity.

\section{ASSOCIATED CONTENT}

\section{S Supporting Information}

228 The Supporting Information is available free of charge on the 229 ACS Publications website at DOI: 10.1021/acs.or230 glett.7b01386.

231 Experimental details; RP-HPLC, RP-UPLC, MS, ${ }^{1} \mathrm{H}$ and $232 \quad{ }^{13} \mathrm{C}$ NMR data; computational details (PDF)

\section{AUTHOR INFORMATION}

\section{Corresponding Author}

235 *E-mail: kaqvo@kemi.dtu.dk.

236 ORCID 1

237 K. Qvortrup: 0000-0003-3828-2069

238 T. E. Nielsen: 0000-0001-8700-1951

239 Notes

240 The authors declare no competing financial interest.

\section{REFERENCES}

242 (1) Minucci, S.; Pelicci, P. G. Nat. Rev. Cancer 2006, 6, 38. 243 Rappoport, Z.; Liebman, J. F. In The Chemistry of Hydroxylamines, 244 Oximes and Hydroxamic Acids; Rappoport, Z., Ed.; Wiley-Interscience: 245 Chichester, 2009; Vols. 1-2.

246 (2) Merrifield, B. R. J. Am. Chem. Soc. 1963, 85, 2149.

247 (3) Moos, W. H.; Green, G. D.; Pavia, M. R. Annu. Rep. Med. Chem. 248 1993, 28, 315.

249 (4) (a) Thouin, E.; Lubell, W. D. Tetrahedron Lett. 2000, 41, 457. 250 (b) Ho, C. Y.; Strobel, E.; Ralbovsky, J., Jr.; Galemmo, R. A. J. Org. 251 Chem. 2005, 70, 4873. (c) Nandurkar, N. S.; Petersen, R.; Qvortrup,
K.; Komnatnyy, V. V.; Taveras, K. M.; Le Quement, S. T.; Frauenlob, 252 R.; Givskov, M.; Nielsen, T. E. Tetrahedron Lett. 2011, 52, 7121. 253 (5) (a) Floyd, C. D.; Lewis, C. N.; Patel, S. R.; Whittaker, M. 254 Tetrahedron Lett. 1996, 37, 8045. (b) Mellor, S. L.; McGuire, C.; Chan, 255 W. C. Tetrahedron Lett. 1997, 38, 3311. (c) Bauer, U.; Ho, W.-B.; 256 Koskinen, A. M. P. Tetrahedron Lett. 1997, 38, 7233. (d) Barlaam, B.; 257 Koza, P.; Berriot, J. Tetrahedron 1999, 55, 7221. (e) Ngu, K.; Patel, D. 258 V. J. Org. Chem. 1997, 62, 7088. (f) Gazal, S.; Masterson, L. R.; Barany, 259 G. J. Pept. Res. 2005, 66, 324. 260

(6) (a) For a definition of an orthogonal protection scheme: Barany, 261 G.; Merrifield, R. B. J. Am. Chem. Soc. 1977, 99, 7363. (b) For a recent 262 review of linkers, see: James, I. W. Tetrahedron 1999, 55, 4855. 263 (c) Yoo, D. J.; Greenberg, M. M. J. Org. Chem. 1995, 60, 3358.264 (7) (a) Holmes, C. P.; Jones, D. G. J. Org. Chem. 1995, 60, 2318. (b) 265 For an overview on photolabile linkers for solid-phase organic 266 synthesis, see: Scott, P. J. H. Linker Strategies in Solid-Phase Organic 267 Synthesis; John Wiley and Sons: 2009.

(8) Qvortrup, K.; Nielsen, T. E. Angew. Chem., Int. Ed. 2016, 55, 269 4472 . 270

(9) Il'ichev, Y. V.; Schwörer, M. A.; Wirz, J. J. Am. Chem. Soc. 2004, 271 $126,4581$. 272

(10) (a) Walbert, S.; Pfleiderer, W.; Steiner, U. E. Helv. Chim. Acta 273 2001, 84, 1601. (b) Corrie, J. E. T.; Barth, A.; Ranjit, V.; Munasinghe, 274 N.; Trentham, D. R.; Hutter, M. C. J. Am. Chem. Soc. 2003, 125, 8546. 275

(11) Schmierer, T.; Bley, F.; Schaper, K.; Gilch, P. J. Photochem. 276 Photobiol., A 2011, 217, 363.

(12) Il'ichev, Y. V.; Wirz, J. J. Phys. Chem. A 2000, 104, 7856.

(13) Dunkin, I. R.; Gębicki, J.; Kiszka, M.; Sanín-Leira, D. J. Chem. 279 Soc., Perkin Trans. 2 2001, 1414. 280

(14) Lill, M. A.; Hutter, M. C.; Helms, V. J. Phys. Chem. A 2000, 104, 281 8283. 282

(15) Schaper, K.; Dommaschke, D.; Globisch, S.; Madani- 283 Mobarekeh, S. A. J. Inf. Rec. 2000, 25, 339.

(16) Paris, M.; Porcelloni, M.; Binaschi, M.; Fattori, D. J. Med. Chem. 285 2008, 51, 1505 .

(17) Petersen, R.; Le Quement, S. T.; Nielsen, T. E. Angew. Chem., 287 Int. Ed. 2014, 53, 11778. 